Short Communication

\title{
Porphyrin Functionalized Graphene for Sensitive Electrochemical Detection of Uric Acid
}

\author{
Yun Yang ${ }^{1,2, *}$, Ruirui Sun ${ }^{l}$, Mingxiang Li ${ }^{1}$, Boya Geng ${ }^{l}$, Jingyi Deng ${ }^{1}$ and, Mingyi Tang ${ }^{1}$ \\ ${ }^{1}$ Department of Application Chemistry, College of Science, Tianjin University of Commerce, \\ Tianjin, 300134, P.R . China; \\ 2 Tianjin Key Laboratory for Prevention and Control of Occupational and Environmental Hazards, \\ Logistics University of PAPF Tianjin, 300162, P.R . China. \\ E-mail: yyun@tjcu.edu.cn
}

doi: $10.20964 / 2016.09 .41$

Received: 10 June 2016 / Accepted: 13 July 2016 / Published: 7 August 2016

\begin{abstract}
In this study, by employing nanobiocomposite from porphyrin modified graphene oxide, we make a stable and sensitive amperometric UA amperometric biosensor. An easy wet-chemical way for synthesizing porphyrin-graphene oxide hybrid nanosheets (T-GOs) was used. Different kinds of ways, including electrochemistry and transmission electron microscopy (TEM), have been used to present how the TPPC-GOs form. Between porphyrin and graphene oxide, there was the synergistic effect. Therefore, the nanosheets greatly performed to the detention of uric acid (UA). Incorporating the porphyrin onto graphene oxide surface caused over doubled increasement of the amperometric reaction to UA of the porphyrin improved electrode. At $0.25 \mathrm{~V}$, UA has been checked successfully. The reaction indicates a great linear range from 0.02 to $5 \mathrm{mM}$ with detection limit $1 \mu \mathrm{M}$. Applied in urine UA and blood, the improved electrode performed well.
\end{abstract}

Keywords: Electrochemistry; Uric acid; Porphyrin; Graphene oxide.

\section{$\underline{\text { FULL TEXT }}$}

(C) 2016 The Authors. Published by ESG (www.electrochemsci.org). This article is an open access article distributed under the terms and conditions of the Creative Commons Attribution license (http://creativecommons.org/licenses/by/4.0/). 